ORIGINAL ARTICLE

\title{
The prevalence and spectrum of $\alpha$ and $\beta$ thalassaemia in Guangdong Province: implications for the future health burden and population screening
}

\author{
X M Xu, Y Q Zhou, G X Luo, C Liao, M Zhou, P Y Chen, J P Lu, S Q Jia, G F Xiao, X Shen, J Li, \\ H P Chen, Y Y Xia, Y X Wen, Q H Mo, W D Li, Y Y Li, L W Zhuo, Z Q Wang, Y J Chen, C H Qin, \\ M Zhong
}

J Clin Pathol 2004;57:517-522. doi: 10.1136/jep.2003.014456

See end of article for authors' affiliations

.....................

Correspondence to: $\operatorname{Dr} X M X_{u}$, Department of Medical Genetics, First Military Medical University, Tonghe 510515, Guangzhou, Guangdong, PR China; gzxuxm@pub.guangzhou. gd.cn

Accepted for publication 28 November 2003

\begin{abstract}
Aim: Thalassaemia is a good candidate disease for control by preventive genetic programmes in developing countries. Accurate population frequency data are needed for planning the control of thalassaemia in the high risk Guangdong Province of southern China.

Methods: In total, 13397 consecutive samples from five geographical areas of Guangdong Province were analysed for both haematological and molecular parameters.

Results: There was a high prevalence of carriers of $\alpha$ thalassaemia (8.53\%), $\beta$ thalassaemia (2.54\%), and both $\alpha$ and $\beta$ thalassaemia (0.26\%). Overall, $11.07 \%$ of the population in this area were heterozygous carriers of $\alpha$ and $\beta$ thalassaemia. The mutation spectrum of $\alpha$ and $\beta$ thalassaemia and its constitution were fully described in this area. This study reports the true prevalence of silent $\alpha$ thalassaemia in the southern China population for the first time. In addition, two novel mutations that give rise to $\alpha$ thalassaemia, one deletion resulting in $\beta$ thalassaemia, and a rare deletion (- $-{ }^{\text {THAl }}$ allele) previously unreported in mainland China were detected. The frequency of the most common mutation, the Southeast Asian type of deletion ( $-{ }^{\text {SEA }}$, accounting for $48.54 \%$ of all $\alpha$ thalassaemias) was similar to the total of two $\alpha^{+}$thalassaemia deletions $\left(-\alpha^{3.7}\right.$ and $-\alpha^{4.2}$, accounting for $47.49 \%$ of $\alpha$ thalassaemia).

Conclusion: Both $\alpha$ and $\beta$ thalassaemia are widely distributed in Guangdong Province of China. The knowledge gained in this study will enable the projected number of pregnancies at risk to be estimated and a screening strategy for control of thalassaemia to be designed in this area.
\end{abstract}

A $\mathrm{s}$ one of inherited disorders of haemoglobin $(\mathrm{Hb})$ synthesis, the thalassaemias form one of the most common single gene disorders in the world, with estimates of gene frequencies ranging from $2.5 \%$ to $15 \%$ in some areas of the tropics and subtropics, including southern China. ${ }^{12}$ There are two main types of thalassaemia, $\alpha$ and $\beta$ thalassaemia. Patients with $\beta$ thalassaemia major inherit two mutant $\beta$ globin alleles and develop a fatal anaemia in early childhood if untreated, whereas fetuses with Hb Barts' hydrops fetalis caused by the homozygous $\alpha^{0}$ thalassaemia gene $(--/--)$ die either in utero or shortly after birth as a result of severe intrauterine anaemia. In addition, most patients with $\mathrm{Hb} \mathrm{H}$, which generally results from the combination of one $\alpha^{+}$thalassaemia $\left(-\alpha /\right.$ or $\left.\alpha^{\mathrm{T}} \alpha /\right)$ and one $\alpha^{0}$ thalassaemia $(--/)$ defect, have moderately severe but variable anaemia, except for the rare case of $\alpha^{0}$ thalassaemia in combination with a non-deletional $\alpha$ globin gene mutation, which can result in hydrops fetalis. ${ }^{23}$

Prenatal testing for $\alpha$ and $\beta$ thalassaemia, with affected homozygous fetuses being aborted is warranted internationally. Programmes-which are based on a combination of increased awareness of mutations in the population, carrier screening, genetic counselling, and prenatal diagnosis-have been successful in reducing these severe forms of $\alpha$ and $\beta$ thalassaemia in several high prevalence areas in developed countries. ${ }^{45}$ The thalassaemias are a major public health problem internationally, but this is particularly so in the developing world, where there are fewer resources for coping with the problem. ${ }^{5-7}$ Although there are many problems in operating a preventive genetic programme aimed at controlling thalassaemia in developing countries, consideration of $\alpha$ and $\beta$ thalassaemia as targets for control will provide us with an opportunity to deliver genetic services in China.

"We investigated the approximate carrier frequency and detailed spectrum of $\alpha$ and $\beta$ thalassaemia in five geographical areas representative of Guangdong Province, based on a large number of random samples"

Previous studies have indicated that there is a high population frequency of thalassaemia in southern China, mainly south of the Yangtze River, particularly in the three most southerly provinces of China-Guangdong, Guangxi and Hainan; in some regions of Guangdong Province, an estimated carrier rate of $5.2-8.5 \%$ for $\alpha$ thalassaemia and $0.5-$ $3.4 \%$ for $\beta$ thalassaemia has been reported..$^{8-11}$ However, much of the data, which are available from the World Health Organisation, were based on studies of very limited numbers of individuals that were carried out many years ago. ${ }^{10}$ In addition, the data do not represent the true prevalence in such high risk Chinese populations because of problems in sample selection and the diagnosis criteria used. Guangdong Province, in which the prevalence of thalassaemia is one of the highest seen in southern China, will be one of the priority administrative areas for launching a large thalassaemia screening programme because of its relatively good economic development and policy support resources. Therefore, to estimate the future burden of disease and the requirements

Abbreviations: $\mathrm{Cl}$, confidence interval; $\mathrm{Hb}$, haemoglobin; $\mathrm{MCV}$, mean corpuscular volume; PCR, polymerase chain reaction; RDB, reverse dot blot 
for its control in this province, accurate population frequency data are badly needed. In our study, we investigated the approximate carrier frequency and detailed spectrum of $\alpha$ and $\beta$ thalassaemia in five geographical areas representative of Guangdong Province, based on a large number of random samples, and assessed the health burden that thalassaemia will pose for Guangdong Province in the future. The data confirmed that approximately $11 \%$ of the population in this area are heterozygous carriers of $\alpha$ and $\beta$ thalassaemia.

\section{DESIGN AND METHODS \\ Population samples}

Figure 1 shows the five regional centres that took part in our study. These regions-Guangzhou (middle), Shantou (east), Zhuhai (south), Zhanjiang (west), and Shaoguan (north)have the largest populations of the five areas of Guangdong Province. In total, 13397 consecutive samples comprising 5605 umbilical blood samples and 7792 adult peripheral blood samples were collected. These last samples were from individuals who received a premarriage medical checkup at one of the large local hospitals in the above five cities. Ninety four per cent of these individuals were ethnic southern Chinese, and most (91\%) were of Guangdong ancestry. We obtained their consent and cooperation for our study. Umbilical blood samples were used for the $\alpha$ thalassaemia survey, whereas peripheral blood samples were used for the $\beta$ thalassaemia survey. To obtain the data on the correlation between $\mathrm{Hb}$ Bart's values, haematological indices, and $\alpha$ thalassaemia genotypes for the future application of newborn screening, we screened for $\alpha$ thalassaemia separately in cord blood samples.

\section{Haematological analysis}

The F820 type blood cell analysis system (CIS Company, Chiba, Japan) was used to determine peripheral blood counts and red blood cell indices using standard procedures. The high speed automatic electrophoresis analytic system (SPIFE; Helena Laboratories, Beaumont, Texas, USA) was used to assess the concentration of haemoglobins $\mathrm{A}, \mathrm{A}_{2}, \mathrm{~F}$, and any abnormal haemoglobin, including $\mathrm{Hb}$ Bart's and $\mathrm{Hb}$ Constant Spring. ${ }^{12}$ The $\alpha^{0}$ thalassaemia traits, $\mathrm{Hb}$ Constant Spring mutation carriers, $\mathrm{Hb} \mathrm{H}$ disease, and hydrops fetalis were preliminarily diagnosed by determining the concentration of Hb Bart's ( $\geqslant 2.0 \%$, values between $2 \%$ and $89 \%$ ) or analysing

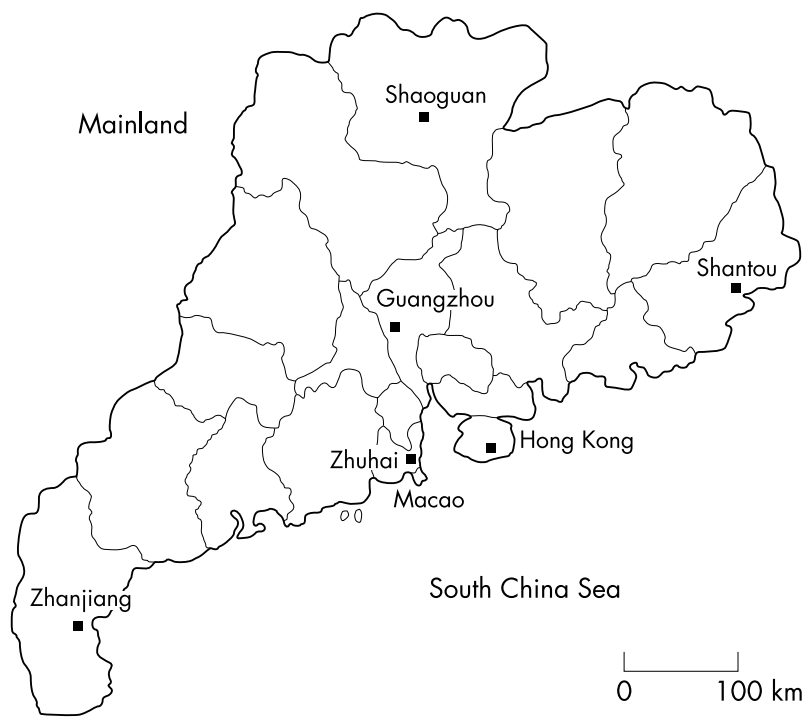

Figure 1 The five regional centres in Guangdong Province that formed the basis of our study. the profile of the $\mathrm{Hb} \mathrm{H}$ or $\mathrm{Hb}$ Constant Spring component in umbilical samples. The diagnosis of these four disorders was confirmed by molecular analysis. Because the silent carriers $\left(\alpha^{+}\right.$thalassaemia traits) were expected to be found in the samples with $\mathrm{Hb}$ Bart's $<2.0 \%$, all umbilical cord blood samples were subject to the detection of two common deletions $\left(-\alpha^{3.7} /\right.$ and $\left.-\alpha^{4.2} /\right)$. The carrier state for phenotypic $\beta$ thalassaemia was diagnosed in samples in which both the concentration of $\mathrm{Hb} \mathrm{A}_{2}$ exceeded 3.5\% and mean corpuscular volume $(\mathrm{MCV})$ was $<80 \mathrm{fl}$.

\section{DNA analysis}

Genomic DNA was extracted from all of the umbilical blood samples and those adult samples with phenotypic $\beta$ thalassaemia. The five known deletional forms of $\alpha$ thalassaemia $\left(--{ }^{\mathrm{SEA}} /, \quad-\alpha^{3.7} /,-\alpha^{4.2} /, \quad-{ }^{\mathrm{THAI}} /\right.$, and - $-{ }^{\mathrm{FIL}} /$ ) were determined by polymerase chain reaction based direct amplification assays. ${ }^{13-15}$ The non-deletional forms of $\alpha$ thalassaemia ( $\mathrm{Hb}$ Constant Spring (TAA $\rightarrow \mathrm{CAA}$ at codon (CD) 142), $\mathrm{Hb}$ Quong Sze (CTG $\rightarrow$ CCG at CD 125), $\Delta \mathrm{CD} 30, \mathrm{AGG} \rightarrow \mathrm{AAG}$ at $\mathrm{CD} 31$, and $\mathrm{GGC} \rightarrow \mathrm{GAC}$ at $\mathrm{CD} 59)$ were defined by the reverse dot blot (RDB) assay using a modified procedure. ${ }^{16}$ To obtain the true prevalence of silent carriers for $\alpha$ thalassaemia, the two common silent alleles, $-\alpha^{3.7} /$ and $-\alpha^{4.2} /$ were genotyped by gap-PCR in all umbilical blood samples. Moreover, to assess the samples with $\mathrm{Hb}$ Bart's $\geqslant 2 \%$ but absence of the above known mutations of $\alpha$ thalassaemia, and to exclude the possibility of an $\alpha$ globin haplotype relevant to producing $\mathrm{Hb}$ Bart's $<2.0 \%$, the $\alpha$ globin genotypes were determined by both Southern blotting $^{17}$ and sequencing of the entire $\alpha 2$ and $\alpha$ l globin genes to identify underlying mutations.

The $\beta$ thalassaemia mutations were identified by the RDB assay, looking for 18 known $\beta$ thalassaemia mutations seen in Chinese populations. ${ }^{18}$ The positive phenotypic samples with unknown $\beta$ thalassaemia mutations were defined by DNA direct sequencing of the entire human $\beta$ globin gene. Samples with borderline $\mathrm{HbA}_{2}$ values between $3.0 \%$ and $3.5 \%$ were also studied in this way. In addition, to investigate the existence of carriers of both $\alpha$ and $\beta$ thalassaemia in our population, all samples with $\beta$ thalassaemia were analysed for possible coinheritance of the four common $\alpha$ thalassaemia mutations $\left(--{ }^{\mathrm{SEA}} /,-\alpha^{3.7} /,-\alpha^{4.2}\right.$, and Hb Constant Spring) seen in the Chinese population.

\section{Statistical analysis}

Current and predicted vital statistics were obtained from the "Population bulletin of the family planning commission of Guangdong Province". ${ }^{19}$ Statistical analyses were conducted with an SPSS software program. The prevalence of different thalassaemia alleles was calculated from the modified HardyWeinberg formula.

\section{RESULTS Population prevalence and mutation spectrum of $\alpha$ and $\beta$ thalassaemia}

Three hundred and seventy one of the 5605 umbilical blood samples $(6.62 \%)$ had $\mathrm{Hb}$ Bart's. Of these 371 samples, 337 were diagnosed as carriers of $\alpha$ thalassaemia, using a PCR based assay to identify known $\alpha$ thalassaemia deletions or point mutations directly. One novel deletion, one novel small insertion at the $\alpha$ l globin gene, and one rare complete $\zeta$ $\alpha$ globin gene cluster deletion were found in the remaining 34 samples with Hb Bart's (the values for these three cases were $1.70 \%, 1.06 \%$, and $6.14 \%$, respectively) by Southern blotting and sequencing of the $\alpha 2$ and $\alpha 1$ globin genes. Two of 34 samples that could not be analysed by Southern blotting because of DNA denaturation had a concentration of $\mathrm{Hb}$ Bart's $>2.0 \%(2.17 \%$ and $5.81 \%$, respectively) and family 
studies showed microcytosis in one of their parents. Thus, these two patients were considered to be $\alpha$ thalassaemia carriers, although $\alpha$ globin mutations were excluded by DNA sequencing of the entire $\alpha 2$ and $\alpha$ l globin genes. The other 29 samples with a lower concentration of Hb Bart's (mean, $0.98 \%$; SD, $0.36 \%$; range, $0.10-1.60 \%$ ) were excluded as $\alpha$ thalassaemia carriers because their $\alpha$ globin gene should be intact $(\alpha \alpha / \alpha \alpha)$, as indicated in other similar studies. ${ }^{20}{ }^{21}$ In addition, 129 of the samples without Hb Bart's were found to be silent carriers of the $-\alpha^{3.7} /\left(102\right.$ cases) and $-\alpha^{4.2} /(27$ cases) deletions. Overall, after discounting the homozygous or compound heterozygous mutant haplotypes, total numbers of $\alpha$ thalassaemia chromosomes were 478 (8.53\%; tables 1 and 2), with a carrier rate of $4.14 \%$ for the Southeast Asian type of deletion $\left(--^{\mathrm{SEA}}\right), 3.10 \%$ for the $-\alpha^{3.7}$ deletion, and $0.95 \%$ for the $-\alpha^{4.2}$ deletion (table 1).

Consistent with previous reports, ${ }^{22-24}$ the Southeast Asian type of deletion $\left(-{ }^{\mathrm{SEA}}\right)$ was the most common mutation, accounting for almost a half of the mutations (48.54\%). Most of the remaining cases $(47.49 \%)$ comprised the two single $\alpha$ globin gene deletions $\left(-\alpha^{3.7} /\right.$ and $\left.-\alpha^{4.2} /\right)$. Overall, these three deletions accounted for $96.03 \%$ of all $\alpha$ thalassaemia cases identified. Interestingly, two patients from Shantou in the east of Guangdong had $\alpha$ thalassaemia Thailand type $\left(--{ }^{\mathrm{THAI}}\right)$, which has not been reported previously in Mainland China. We found no $--^{\mathrm{FIL} /}$ deletions or $\Delta \mathrm{CD}$ 30, CD 31, or CD59 mutations (table 1).

One hundred and ninety eight of the 7792 blood samples screened $(2.54 \%)$ had $\beta$ thalassaemia mutations (tables 1 and $3)$, including three diagnosed by haematological analysis. These three patients had been diagnosed as $\beta$ thalassaemia carriers because their haemoglobin $\mathrm{A}_{2}$ concentrations were

Table 1 Results of screening of cord blood samples from 5605 newborns for $\alpha$ thalassaemia and blood samples from 7792 adults for $\beta$ thalassaemia in Guangdong Province

\begin{tabular}{|c|c|c|}
\hline Variable & $\begin{array}{l}\text { Number of samples } \\
\text { or alleles }\end{array}$ & Per cent \\
\hline Samples with Hb Bart's & 371 & 6.62 \\
\hline$\alpha$ Thalassaemia* & 340 & - \\
\hline Normal & 29 & - \\
\hline Undetermined & 2 & - \\
\hline Silent carriers without $\mathrm{Hb}$ Bart's & 129 & 2.30 \\
\hline$\left(-\alpha^{3.7}\right)$ Deletion & 102 & - \\
\hline$\left(-\alpha^{4.2}\right)$ Deletion & 27 & - \\
\hline$\alpha$ Thalassaemia chromosomes & 478 & 8.53 \\
\hline$\left(--{ }^{\text {SEA }}\right)$ Deletion & 232 & 4.14 \\
\hline$\left(-\alpha^{3.7}\right)$ Deletion & 174 & 3.10 \\
\hline$\left(-\alpha^{4.2}\right)$ Deletion & 53 & 0.95 \\
\hline$\left(-\alpha^{\mathrm{CS}}\right)$ Mutation & 10 & 0.18 \\
\hline$\left(-{ }^{\text {THAl }}\right)$ Deletion & 2 & 0.04 \\
\hline$\left(-\alpha^{Q S}\right)$ Mutation & 2 & 0.04 \\
\hline$(--11.1)$ Deletiont & 1 & 0.02 \\
\hline$\alpha 1 C D 118(+\mathrm{TCA}) \dagger$ & 1 & 0.02 \\
\hline$\zeta-\alpha$ Gene deletion & 1 & 0.02 \\
\hline Undetermined & 2 & 0.04 \\
\hline$\beta$ Thalassaemia chromosomes & 198 & 2.54 \\
\hline Deletion of CTTT at codons $41-42$ & 72 & 0.92 \\
\hline $\mathrm{C} \rightarrow \mathrm{T}$ at position 654 in IVS2 & 49 & 0.63 \\
\hline$A \rightarrow G$ at nucleotide -28 & 33 & 0.42 \\
\hline $\mathrm{G} \rightarrow \mathrm{A}$ at codon $26(\mathrm{Hb} \mathrm{E})$ & 10 & 0.13 \\
\hline $\mathrm{A} \rightarrow \mathrm{T}$ at codon 17 & 8 & 0.10 \\
\hline Insertion of $A$ at codons $71-72$ & 7 & 0.09 \\
\hline $\mathrm{G} \rightarrow \mathrm{T}$ at codon 43 & 7 & 0.09 \\
\hline$A \rightarrow G$ at nucleotide -29 & 4 & 0.05 \\
\hline Insertion of $A$ at codons $27-28$ & 4 & 0.05 \\
\hline$\beta$ Gene deletion $\dagger$ & 1 & 0.01 \\
\hline Undetermined & 3 & 0.04 \\
\hline
\end{tabular}

*The number of carriers with both deletional and non-deletional mutations and patients with hydrops fetalis and $\mathrm{Hb} \mathrm{H}$ disease; tnovel mutations found during our survey. above 3.5\% (range, 3.6-6.6\%) and their MCV values were $<80 \mathrm{fl}$ (range, 64-74 fl), although sequence analysis of the entire $\beta$ globin gene revealed no mutations. One of these patients, who was from the north of Guangdong (Shaoguan), had a $\beta$ globin gene deletion, which was diagnosed by screening for all five polymorphic sites of the $2 \mathrm{~kb} \beta$ globin gene fragments amplified from the suspected sample (table 1). The mutation profiles from the five different geographical areas showed that about $90 \%$ of the mutations were accounted for by four to six common mutations, in agreement with previous studies, ${ }^{22} 24$ although there were slight differences between these areas in the distribution of the mutations.

Twenty individuals were carriers of both $\alpha$ and $\beta$ thalassaemia mutations and, in total, 11 combinations of the two diseases were found, with a rate of $0.26 \%$ (20 of 7792). Twenty three carriers of six different haemoglobin variants were identified by haemoglobin electrophoresis, including $10 \mathrm{Hb}$ E carriers (table 1) and one heterozygote with haemoglobin $\mathrm{C}$, which has not previously been encountered in a Chinese population (data not shown).

\section{The predicted future health burden}

On average, the prevalence was $2.54 \%$ (95\% confidence interval (CI), $2.19 \%$ to $2.89 \%$ ) for $\beta$ thalassaemia, $4.14 \%$ (95\% CI, 3.87 to $4.41 \%$ ) for $\alpha$ thalassaemia caused by the Southeast Asian deletion (- $-{ }^{\mathrm{SEA}}$ ), and $4.05 \%$ (95\% CI, 3.79\% to $4.31 \%$ ) for $\alpha$ thalassaemia caused by a single $\alpha$ globin gene deletion or mutation in Guangdong Province. With the current annual birth rate of about one million, the estimated numbers of pregnancies each year in Guangdong in which the fetus would be at risk for $\beta$ thalassaemia major or intermedia, Bart's hydrops fetalis, and $\mathrm{Hb} \mathrm{H}$ disease are 645 (95\% CI, 480 to 835 ), 1714 (95\% CI, 1498 to 1945 ), and 1677 (95\% CI, 1467 to 1901$)$, respectively.

\section{DISCUSSION}

Preventive genetic programmes based on hospital based screening and prenatal diagnosis have been in use for many years in a few cities in Guangdong Province, such as in Guangzhou, which started prospective genetic screening in January of 1993. To date, 37758 pregnant women and 4503 of their husbands have been screened, and $1 / 17$ of all pregnant women in this city are referred annually for prenatal diagnosis of thalassaemia. Consequently, 51 and 18 fetuses with $\alpha$ and $\beta$ thalassaemia, respectively, have been aborted. However, only a small proportion of the population benefits from such control programmes. A community based or nationwide programme, ${ }^{45}$ such as those practised in Italy, Cyprus, and other developed nations where thalassaemia is common, which comprises public education, a cost effective screening strategy, and adequate antenatal services, is needed in Guangdong. To design such a preventive programme and to assess the public health burden in the Guangdong population accurate population frequency data on $\alpha$ and $\beta$ thalassaemia in this area are required.

We have obtained data on the prevalence and mutation patterns of $\alpha$ and $\beta$ thalassaemia based on sampling the population from five representative geographical areas of Guangdong Province, southern China. The frequency of $\alpha$ and $\beta$ thalassaemia was similar in these five different areas, except that there was a lower prevalence of both $\alpha$ and $\beta$ thalassaemia in Shantou, which is in the east of the province. We do not know the reason for this because historically all five areas were afflicted with endemic malaria. However, it may reflect differences in the background of the populations - the population of Shantou is unusual because many people migrated to the region from the central part of China hundreds of years ago. It would be interesting to 
Table $2 \alpha$ Globin genotype and $\alpha$ thalassaemia frequencies from five different regions in Guangdong Province

\begin{tabular}{|c|c|c|c|c|c|c|c|c|c|c|c|c|}
\hline \multirow[b]{2}{*}{ Genotype } & \multicolumn{2}{|c|}{ Guangzhou } & \multicolumn{2}{|c|}{ Zhanjiang } & \multicolumn{2}{|c|}{ Zhuhai } & \multicolumn{2}{|c|}{ Shaoguan } & \multicolumn{2}{|c|}{ Shantou } & \multicolumn{2}{|c|}{ Total } \\
\hline & $\mathrm{N}$ & $\%$ & $\mathbf{N}$ & $\%$ & $\mathbf{N}$ & $\%$ & $\mathbf{N}$ & $\%$ & $\mathrm{~N}$ & $\%$ & $\mathbf{N}$ & $\%$ \\
\hline$-{ }^{\mathrm{SEA}} / \alpha \alpha$ & 35 & 39.8 & 49 & 55.7 & 72 & 52.6 & 48 & 48.0 & 17 & 29.3 & 221 & 46.9 \\
\hline$-\alpha^{3.7 / \alpha \alpha}$ & 38 & 43.2 & 24 & 27.3 & 41 & 29.9 & 41 & 41.0 & 28 & 48.3 & 172 & 36.5 \\
\hline$-\alpha^{4.2} / \alpha \alpha$ & 12 & 13.7 & 13 & 14.8 & 16 & 11.7 & 5 & 5.0 & 7 & 12.1 & 53 & 11.3 \\
\hline$-{ }^{T H} \mathrm{THI}^{\prime} / \alpha \alpha$ & 0 & 0 & 0 & 0 & 0 & 0 & 0 & 0 & 2 & 3.5 & 2 & 0.4 \\
\hline$\alpha^{\mathrm{CS}} \alpha / \alpha \alpha$ & 1 & 1.1 & 1 & 1.1 & 4 & 3.0 & 3 & 3.0 & 1 & 1.7 & 10 & 2.2 \\
\hline$\alpha^{\mathrm{QS}} \alpha / \alpha \alpha$ & 0 & 0 & 0 & 0 & 1 & 0.7 & 0 & 0 & 0 & 0 & 1 & 0.2 \\
\hline$--{ }^{S E A} /-\alpha^{3.7}$ & 1 & 1.1 & 0 & 0 & 0 & 0 & 1 & 1.0 & 0 & 0 & 2 & 0.4 \\
\hline$-{ }^{\mathrm{SEA}} / \alpha^{\mathrm{QS}} \alpha$ & 0 & 0 & 0 & 0 & 1 & 0.7 & 0 & 0 & 0 & 0 & 1 & 0.2 \\
\hline - - SEA $/-\_$SEA & 0 & 0 & 1 & 1.1 & 0 & 0 & 2 & 2.0 & 1 & 1.7 & 4 & 0.9 \\
\hline$--11.1 / \alpha \alpha$ & 1 & 1.1 & 0 & 0 & 0 & 0 & 0 & 0 & 0 & 0 & 1 & 0.2 \\
\hline alCD 118 (+TCA) & 0 & 0 & 0 & 0 & 0 & 0 & 0 & 0 & 1 & 1.7 & 1 & 0.2 \\
\hline$\zeta-\alpha$ Gene deletion & 0 & 0 & 0 & 0 & 1 & 0.7 & 0 & 0 & 0 & 0 & 1 & 0.2 \\
\hline Undetermined* & 0 & 0 & 0 & 0 & 1 & 0.7 & 0 & 0 & 1 & 1.7 & 2 & 0.4 \\
\hline Total & 88 & 100 & 88 & 100 & 137 & 100 & 100 & 100 & 58 & 100 & 471 & 100 \\
\hline
\end{tabular}

investigate this regional difference by widespread sampling and further haplotyping of samples to compare their genomic organisation with others. Our study also confirms that despite slight regional variation, the spectrum of both $\alpha$ and $\beta$ thalassaemia mutations is similar to that previously described in southern China. ${ }^{92-25}$ A few rare mutations were identified in the individuals with typical $\alpha$ or $\beta$ thalassaemia trait. In five patients with $\alpha$ thalassaemia trait there was one novel type of deletion (an $\sim 11.1 \mathrm{~kb}$ deletion encompassing the $\alpha 2$ and $\alpha$ l globin genes), one novel TCA insertion between codons 118 and 119 of the $\alpha$ l globin gene, two Thailand deletions, and one deletion of the complete $\zeta$ $\alpha$ globin gene cluster previously described in Chinese. ${ }^{24}$ In addition, there was one possible $\beta$ thalassaemia deletion (table 1). A detailed description of the analysis of these six individuals will be the subject of a separate report. Interestingly, this was the first time that a relatively common $\alpha^{0}$ thalassaemia allele, the Thailand deletion previously described in Southeast Asian and Taiwan aboriginals, ${ }^{26}{ }_{27}$ was detected in two individuals from the east of Guangdong, mainland China. Whether the molecular evolution of this deletion differs between the Chinese and Southeast Asian forms remains to be determined. Triplicated $\alpha$ globin genes were not investigated in our study.

We found a high prevalence of two silent deletions $\left(-\alpha^{3.7}\right.$ / and $-\alpha^{4.2} /$ ) involving a single $\alpha$ globin gene $(4.05 \%)$, which is close to the incidence of the $-{ }^{\text {SEA }}$ deletion $(4.14 \%)$. This incidence is much higher than that reported recently from
Hong Kong (0.5\%), ${ }^{24}$ where many carriers of such mutations may have escaped detection as a result of their screening strategy. In fact, this is the first report of the true prevalence of silent $\alpha$ thalassaemia in southern China because our data are based on $\alpha$ globin gene mutations screened by molecular diagnostic assays involving gap-PCR and direct DNA sequencing. Previous studies have not estimated the true prevalence of silent $\alpha$ thalassaemia in China because of different survey aims in some investigations, ${ }^{24} 28$ or inappropriate diagnostic criteria, such as using the concentration of Hb Bart's below $2.0 \%$ as a positive criteria for silent $\alpha$ thalassaemia or an MCV value $<80 \mathrm{fl}$ as a diagnostic cutoff value for all $\alpha$ thalassaemias involving silent carrier deletion. ${ }^{8} 92930$ The fact that silent phenotypes in both umbilical and peripheral blood samples may escape detection based on haematological investigations alone is often ignored. The prevalence of silent $\alpha$ thalassaemia reported here will be extremely useful for us to evaluate the projected numbers of at risk pregnancies annually and the number of patients with $\mathrm{Hb} \mathrm{H}$ disease.

\begin{abstract}
"A community based or nationwide programme, such as those practised in Italy, Cyprus, and other developed nations where thalassaemia is common, which comprises public education, a cost effective screening strategy, and adequate antenatal services, is needed in Guangdong"
\end{abstract}

Our results showed that of $198 \beta$ thalassaemia carriers, 20 coinherited $\alpha$ thalassaemia in the form of the deletion of two

\begin{tabular}{|c|c|c|c|c|c|c|c|c|c|c|c|c|}
\hline \multirow[b]{2}{*}{ Genotype } & \multicolumn{2}{|c|}{ Guangzhou } & \multicolumn{2}{|c|}{ Zhanjiang } & \multicolumn{2}{|c|}{ Zhuhai } & \multicolumn{2}{|c|}{ Shaoguan } & \multicolumn{2}{|c|}{ Shantou } & \multicolumn{2}{|l|}{ Total } \\
\hline & $\mathrm{N}$ & $\%$ & $\mathrm{~N}$ & $\%$ & $\mathrm{~N}$ & $\%$ & $\mathrm{~N}$ & $\%$ & $\mathbf{N}$ & $\%$ & $\mathrm{~N}$ & $\%$ \\
\hline CD41/42 (-TCTT) & 14 & 31.8 & 16 & 32.7 & 12 & 34.3 & 27 & 49.1 & 3 & 20.0 & 72 & 36.4 \\
\hline IVS-2-654 (C $\rightarrow T)$ & 20 & 45.5 & 13 & 26.6 & 3 & 8.5 & 9 & 16.4 & 4 & 26.7 & 49 & 24.8 \\
\hline$-28(A \rightarrow G)$ & 5 & 11.4 & 8 & 16.3 & 9 & 25.7 & 7 & 12.8 & 4 & 26.7 & 33 & 16.7 \\
\hline$\beta^{\mathrm{E}}: \mathrm{CD} 26(\mathrm{G} \rightarrow \mathrm{A})$ & 0 & 0 & 5 & 10.2 & 3 & 8.5 & 1 & 1.8 & 1 & 6.7 & 10 & 5.1 \\
\hline $\mathrm{CD} 17(\mathrm{~A} \rightarrow \mathrm{T})$ & 0 & 0 & 4 & 8.2 & 1 & 2.9 & 1 & 1.8 & 2 & 13.2 & 8 & 4.0 \\
\hline CD71/72 (+A) & 2 & 4.5 & 1 & 2.0 & 2 & 5.7 & 2 & 3.6 & 0 & 0 & 7 & 3.5 \\
\hline $\mathrm{CD} 43(\mathrm{G} \rightarrow \mathrm{T})$ & 0 & 0 & 0 & 0 & 2 & 5.7 & 5 & 9.1 & 0 & 0 & 7 & 3.5 \\
\hline$-29(A \rightarrow G)$ & 3 & 6.8 & 0 & 0 & 1 & 2.9 & 0 & 0 & 0 & 0 & 4 & 2.0 \\
\hline CD27/28 (+C) & 0 & 0 & 1 & 2.0 & 1 & 2.9 & 2 & 3.6 & 0 & 0 & 4 & 2.0 \\
\hline$\beta$ Gene deletion* & 0 & 0 & 0 & 0 & 0 & 0 & 1 & 1.8 & 0 & 0 & 1 & 0.5 \\
\hline Undetermined & 0 & 0 & 1 & 2.0 & 1 & 2.9 & 0 & 0 & 1 & 6.7 & 3 & 1.5 \\
\hline Total & 44 & 100 & 49 & 100 & 35 & 100 & 55 & 100 & 15 & 100 & 198 & 100 \\
\hline
\end{tabular}


( 14 cases of $-{ }^{\text {SEA }}$ ) or one (four cases of $-\alpha^{3.7}$; two cases of $-\alpha^{4.2}$ ) structural $\alpha$ globin gene(s). They accounted for $0.26 \%$ (20 of 7792) of the population from Guangdong Province, and confirmed that double heterozygosity for $\alpha$ and $\beta$ thalassaemia is not rare in areas where thalassaemia is common. This raises practical issues when using haematological tests as the screening methodology because there are no significant haematological differences between coinherited $\alpha$ and $\beta$ thalassaemia and $\beta$ thalassaemia ${ }^{2}$; this was confirmed by the results of our haematological analysis of these 20 samples (data not shown), although MCV and $\alpha$ to $\beta$ ratio values may be raised to varying degrees in coinherited $\alpha$ and $\beta$ thalassaemia. To prevent concordant $\alpha$ or $\beta$ thalassaemia heterozygotes from escaping detection, as has been reported for $\beta$ thalassaemia carriers in Hong Kong, ${ }^{31}$ we suggest that $\alpha$ thalassaemia mutations should be screened for in all $\beta$ thalassaemia couples in the Guangdong area. This will allow us to offer comprehensive genetic counselling to those couples with $\alpha$ or $\beta$ thalassaemia who are concordant and discordant heterozygotes. For example, in a couple who are discordant thalassaemia heterozygotes, even for the worst scenario, in which a fetus inherited both of the parents' mutant genes, the results would still be benign. However, if the parent with $\beta$ thalassaemia trait is a compound $\alpha$ and $\beta$ trait, then the outcome may not be benign because there is the risk of a fetus being affected by hydrops fetalis.

Guangdong is located in the southeastern coastal region of China and has a resident population of 78 million and an annual birth rate of one million (official web site for population and family planning of Guangdong Province). ${ }^{19}$ Because of the extremely large population, issues relevant to thalassaemia have a large impact on the public health burden. The data from our report can help us to estimate the numbers of pregnancies at risk for the three main severe forms of thalassaemia: $\beta$ thalassaemia major, hydrops fetalis, and $\mathrm{Hb} \mathrm{H}$ disease. However, it will be difficult for us to predict the numbers of patients homozygous for $\beta$ thalassaemia major at any one time because there are no epidemiological data regarding the survival of such patients in China. Because of the lack of regular treatment and optimal health care for this disease, most patients do not survive to adolescence in developing countries (they often die before 5 years of age in most rural areas of southern China), although the life span of these patients is very variable, depending on whether or not optimal health care is given. In contrast, the clinical phenotype of patients with $\mathrm{Hb} \mathrm{H}$ disease is usually milder, although at least a half of these patients need to be treated with transfusion. ${ }^{32}$ According to our data, the number of patients with $\mathrm{Hb} \mathrm{H}$ disease in this area should be extremely large. In Guangdong, the incidence of $\mathrm{Hb} \mathrm{H}$ disease is approximately four in 10000 live births, with 419 affected babies born annually. From gene frequency data, the numbers of affected individuals born each year, and based on the assumption that with current treatment these patients live to about 60 years, we predict that more than 25140 patients will require regular treatment for $\mathrm{Hb} \mathrm{H}$ disease at any one time in Guangdong. Because most patients with $\mathrm{Hb} \mathrm{H}$ disease can lead normal lives and have treatable late complications, prenatal testing for the disease in usually unwarranted..$^{32}$ However, it will be a considerable public health burden for our developing country to expend a large number of medical resources in taking care of these patients.

With a better knowledge of the thalassaemia mutations present in the population, it may be possible to develop a more rational approach to population screening for control and counselling of disease in this area. Our study found that just five $\beta$ thalassaemia alleles and four $\alpha$ thalassaemia alleles make up more than $90 \%$ of the mutant alleles in the

\section{Take home messages}

- There was a high prevalence of carriers of $\alpha$ thalassaemia $(8.53 \%), \beta$ thalassaemia $(2.54 \%)$, and both $\alpha$ and $\beta$ thalassaemia $(0.26 \%)$ in the Guangdong Province of China

- Overall, $11.07 \%$ of the population in this area were heterozygous carriers of $\alpha$ and $\beta$ thalassaemia

- Two novel mutations that give rise to $\alpha$ thalassaemia, one deletion resulting in $\beta$ thalassaemia, and a rare deletion (- $-{ }^{\text {THAl }}$ allele) previously unreported in mainland China were detected

- The knowledge gained in this study will enable the projected number of pregnancies at risk to be estimated and a screening strategy for control of thalassaemia to be designed in this area

population. Thus, a limited panel of DNA probes or specific primers for PCR based hybridisation or direct amplification techniques could satisfy the requirements for population screening and prenatal diagnosis. In addition, it will be important to set up a regional DNA diagnostic reference laboratory that could also identify rare mutations and support the screening programme. Despite completing a full sequence analysis of $\alpha$ and $\beta$ globin genes, we were unable to characterise $0.75 \%$ (five of 669 ) of the underlying mutations causing thalassaemia in our samples. The practice issue arising from our study is the counselling and management of $\mathrm{Hb} \mathrm{H}$ disease. We found three patients with $\mathrm{Hb} \mathrm{H}$ disease and four with hydrops fetalis (table 2). Hb $\mathrm{H}$ disease, like hydrops fetalis, will probably form one of the most common homozygous $\alpha$ thalassaemias in Guangdong and other high risk areas of Southern China. Because prenatal testing is unwarranted for this disease, ${ }^{32}$ we emphasise the importance of diagnosis using molecular analysis for later counselling and disease management. In our population, $\mathrm{Hb} \mathrm{H}$ disease was usually caused by compound heterozygosity for the most common disease allele (the SEA deletion) and one of the other four alleles: the two $\alpha^{+}$thalassaemia alleles $\left(-\alpha^{3.7} /\right.$ and $-\alpha^{4.2} /$ ) and two $\alpha 2$ globin gene mutations ( $\alpha^{\mathrm{CS}} \alpha /$ and $\left.\alpha^{\mathrm{QS}} \alpha /\right)$.

\section{ACKNOWLEDGMENTS}

We thank Dr E Ma for critically reading the manuscript and Dr PY Chen for his excellent suggestions in the epidemiological survey. This study was partially funded by the Fund of National Key Basic Research Developments Programme of the Ministry of Science and Technology, PR China for the key project grants (001CB510308), by Research Foundation for Key Project from Guangdong Provincial Department of Science and Technology and Guangdong Provincial Department of Health (99B06704G), and by PLA grants for outstanding young scientist in medical research (01J010 to $\mathrm{X} \mathrm{Xu}$ ).

\section{Authors' affiliations}

X M Xu, S Q Jia, Q H Mo, Department of Medical Genetics, First Military Medical University, Guangzhou 510515, Guangdong, PR China Y Q Zhou, G F Xiao, W D Li, Zhuhai Municipal Maternity and Child Healthcare Hospital, Zhuhai 519000, Guangdong, PR China

G X Luo, X Shen, Y Y Li, The Affiliated Hospital, Guangdong Medical College, Zhanjiang 524001, Guangdong, PR China

C Liao, J Li, L W Zhuo, Guangzhou Municipal Maternity and Child Healthcare Hospital, Guangzhou 510180, Guangdong, PR China M Zhou, H P Chen, Z Q Wang, Guangdong Provincial Peoples' Hospital, Guangzhou 510080, Guangdong, PR China

P Y Chen, Y Y Xia, Y J Chen, Shaoguan Municipal Maternity and Child Healthcare Hospital, Shaoguan 512026, Guangdong, PR China

J P Lu, Y X Wen, C H Qin, Shantou Municipal Second Peoples' Hospital, Shantou 515011, Guangdong, PR China 
M Zhong, Department of Obstetrics and Gynaecology, Nanfang Hospital, First Military Medical University, Guangzhou 510515, Guangdong, PR China

\section{REFERENCES}

1 Weatherall DJ. Phenotype-genotype relationships in monogenic disease: lessons from the thalassaemias. Nat Rev Genet 2001;2:245-55.

2 Forget BG. Thalassemia syndromes. In: Hoffman R, Benz EJ Jr, Shattil SJ, et al, eds. Hematology: basic principles and practice, 3rd ed. Singapore: Harcourt Asia PTE, 2000:485-510

3 Chui DH, Fucharoen S, Chan V. Hemoglobin H disease: not necessarily a benign disorder. Blood 2003;101:791-800.

4 Cao A, Rosatelli MC, Monni G, et al. Screening for thalassemia: a model of success. Obstet Gynecol Clin North Am 2002;29:305-28, vi-vii.

5 Weatherall DJ, Clegg JB. Thalassemia-a global public health problem. Nat Med 1996;2:847-9.

6 World Health Organisation. Human genetics programme: services for the prevention and management of genetic disorders and birth defects in developing countries. Geneva: WHO, 1999.

7 de Silva S, Fisher CA, Premawardhena A, et al. Thalassaemia in Sri Lanka: implications for the future health burden of Asian populations. Sri Lanka thalassaemia study group. Lancet 2000;355:786-91.

8 National Hemoglobinopathy Cooperative Study Group. A survey of hemoglobinopathies in 600,000 peoples from 20 provinces, autonomous regions and municipalities. Chin J Med 1983;64:382-5.

9 Zeng YT, Huang SZ. Disorders of haemoglobin in China. J Med Genet 1987:24:578-83.

10 World Health Organisation. Hereditary disease programme: guidelines for the control of haemoglobin disorders. Geneva: WHO, 1994.

11 Xu X, Liao C, Liu Z, et al. Antenatal screening and fetal diagnosis of betathalassemia in a Chinese population: prevalence of the beta-thalassemia trait in the Guangzhou area of China. Hum Genet 1996;98:199-202.

12 Keating J, Pattison A, Sherwood RA. Evaluation of the Helena REP automated electrophoresis instrument for the measurement of glycated haemoglobin. Ann Clin Biochem 1991;28:185-6.

13 Xiao WW, Xu XM, Liu ZY. Rapid detection of $\alpha$-thalassemia of Southeast Asian deletion by polymerase chain reaction and its application to prenatal diagnosis. Zhonghua Yi Xue Yi Chuan Xue Za Zhi 2000;21:192-4.

14 Zhao $Y$, Zhong M, Liu Z, et al. Rapid detection of the common $\alpha$-thalassemia-2 determinants by PCR assay. Zhonghua Yi Xue Yi Chuan Xue Za Zhi $2001 ; 18: 216-18$

15 Liu YT, Old JM, Miles K, et al. Rapid detection of alpha-thalassaemia deletions and alpha-globin gene triplication by multiplex polymerase chain reactions. Br J Haematol 2000;108:295-9.
16 Chan V Yam I, Chen FE et al. A reverse dot-blot method for rapid detection of non-deletion $\alpha$ thalassaemia. $\mathrm{Br} J$ Haematol 1999; 104:513-15.

17 Waye JS, Eng B, Cai SP, et al. Carrier detection and prenatal diagnosis of hemoglobinopathies in Ontario. Clin Invest Med 1993; 16:358-71.

18 Zhang JZ, Xu XM, Ma WF, et al. Reverse dot blot analysis: a rapid prenatal diagnostic approach for $\beta$-thalassemia mutations in Chinese. Chin Sci Bull 1994:39:1059-62.

19 Official web site for population and family planning of Guangdong Province (http://www.gdpic.gov.cn/)

20 Fucharoen S, Winichagoon P, Wisedpanichkii R, et al. Prenatal and postnatal diagnoses of thalassemias and hemoglobinopathies by HPLC. Clin Chem 1998;44:740-8

21 Kyriacou K, Kyrri A, Kalogirou E, et al. Hb Bart's levels in cord blood and alpha-thalassemia mutations in Cyprus. Hemoglobin 2000;24:171-80.

22 Liang $\mathbf{R}$, Liang $\mathrm{S}$, Jiang $\mathrm{NH}$, et al. $\alpha$-and $\beta$-thalassemia among Chinese children in Guangxi Province, PR China: molecular and haematological characterization. Br J Haematol 1994;86:351-4.

23 Zeng YT, Huang SZ. Alpha-globin gene organisation and prenatal diagnosis of alpha-thalassaemia in Chinese. Lancet 1985;1:304-7.

24 Lau YL, Chan LC, Chan YY, et al. Prevalence and genotypes of $\alpha$ - and $\beta$ thalassemia carriers in Hong Kong-implications for population screening N Engl J Med 1997;336:1298-301.

25 Zhang JZ, Cai SP, He X, et al. Molecular basis of beta thalassemia in south China. Strategy for DNA analysis. Hum Genet 1988;78:37-40.

26 Fischel-Ghodsian N, Vickers MA, Seip M, et al. Characterization of two deletions that remove the entire human zeta-alpha globin gene complex $\left(-{ }^{\text {THAl }}\right.$ and - - ${ }^{\mathrm{FL}}$ ). Br J Haematol 1988;70:233-8.

27 Ko TM, Chen TA, Hsieh Ml, et al. Alpha-thalassemia in the four major aboriginal groups in Taiwan. Hum Genet 1993;92:79-80.

28 Chan LC, Ma SK, Chan AY, et al. Should we screen for globin gene mutations in blood samples with mean corpuscular volume (MCV) greater than $80 \mathrm{fl}$ in areas with a high prevalence of thalassaemia? J Clin Pathol 2001;54:317-20.

29 Wang SW, Wang $\mathrm{LM}$, Zhang BH, et al. A survey of $\mathrm{Hb}$ Bart in cord blood and the $\alpha$-globin gene in South China. Birth Defects Orig Artic Ser 1987;23:23-30.

30 Zhao JB, Zhao L, Gu YC, et al. Types of alpha-globin gene deficiencies in Chinese newborn babies in the Guangxi region, PR China. Hemoglobin 1992;16:325-8.

31 Lam YH, Tang MH. Risk of neural tube defects in the offspring of thalassaemia carriers in Hong Kong Chinese. Prenat Diagn 1999;19:1135-7.

32 Chen FE, Ooi C, Ha SY, et al. Genetic and clinical features of hemoglobin H disease in Chinese patients. N Engl J Med 2000;343:544-50. 